\title{
Compact Narrow Band Non-Degenerate Dual-Mode Microstrip Filter with Etched Square Lattices
}

\author{
P. K. Singhal, Suman Mathur, R. N. Baral
}

Department of Electronics, Madhav Institute of Technology and Science, Gwalior, India. Email:pks_65@yahoo.com

Received September $11^{\text {th }}, 2009$; revised October $13^{\text {th }}, 2009$; accepted October $17^{\text {th }}, 2009$.

\begin{abstract}
A compact narrowband non-degenerate dual-mode microstrip filter with square shape cuts is presented. The structure is developed by loading the conventional non-degenerate dual-mode resonator by open circuit stubs at two opposite corners. The filter bandwidth is controlled by only decreasing the higher cutoff frequency of the conventional type. With Square shape cuts, return loss is improved. A 20\% fractional bandwidth filter is designed and implemented on FR4 material with 4.4 dielectric constant and $1.6 \mathrm{~mm}$ thickness at center frequency of $1.5 \mathrm{GHz}$ with passband of $1.3 \mathrm{GHz}$ to 1.6 GHz. Analysis has been achieved using the IE3D simulator. Experimental results do agree with simulations.
\end{abstract}

Keywords: Microstrip, Dual Mode, Narrowband Filter, Square Patch Resonator

\section{Introduction}

Now-a-days compact microwave filters are widely used in various wireless communication applications. Dualmode resonators have been used for such purposes. Each of dual-mode resonators act as a doubly tuned resonant circuit and therefore the number of resonators required for a given filter is reduced by half, resulting in a compact configuration. Dual-mode microstrip resonators have the advantages of low profile, simple fabrication, ease of integration in addition to low cost. The first microstrip dual-mode filter was presented by Wolff [1] in 1972 . Degenerate modes based filters have been investigated in various topologies such as square patch [2], circular patch, triangular patch, square loop [3], circular ring [4] and meander shape [5]. Square and circular patches structures have negligible conductor loss but suffer from higher radiation loss. However, square loop and circular ring structures have less radiation loss but suffer from higher conductor loss, especially for thin strip conductors [2]. Degenerate dual mode filters have usually narrow bandwidth of $(<\% 5)$. Filters with higher bandwidth up to $25 \%$ have been investigated using non-degenerate dual-mode structure [6-7].

\section{Proposed Structure and Modes of Operation}

The fields within a square patch resonator can be ex- panded by the $\mathrm{TM}^{\mathrm{z}}{ }_{\mathrm{mn} 0}$ modes [2], where ' $\mathrm{z}$ ' is perpendicular to the ground plane. The two fundamental degenerate modes correspond to $\mathrm{TM}^{\mathrm{z}}{ }_{100}$ and $\mathrm{TM}^{\mathrm{z}}{ }_{010}$ and the first higher order mode correspond to $\mathrm{TM}^{\mathrm{z}}{ }_{110}[6]$. These three modes can be excited simultaneously by a square shape resonator with feed lines, as shown in Figure 1. The simulated response is shown in Figure 2.

The etching of slots in square patch resonator as shown in Figure 3 decreases the resonance frequencies of the

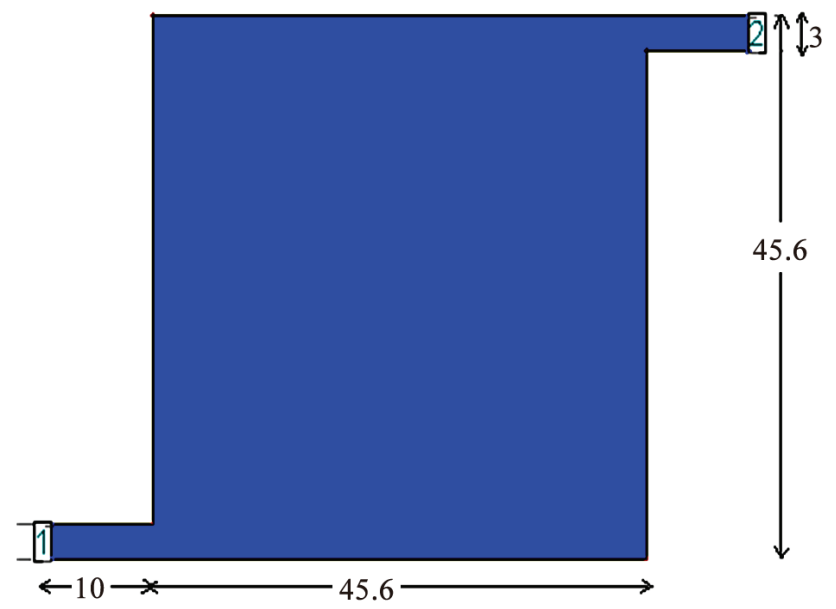

Figure 1. Layout of square patch resonator with feed lines (All dimensions are in $\mathbf{m m}$ ) 


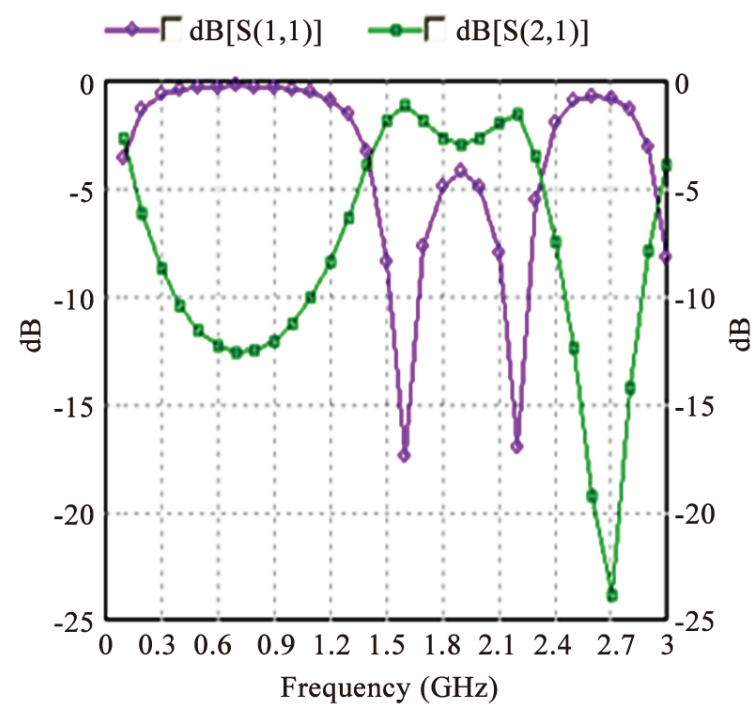

Figure 2. Simulated response of square patch resonator with feed lines

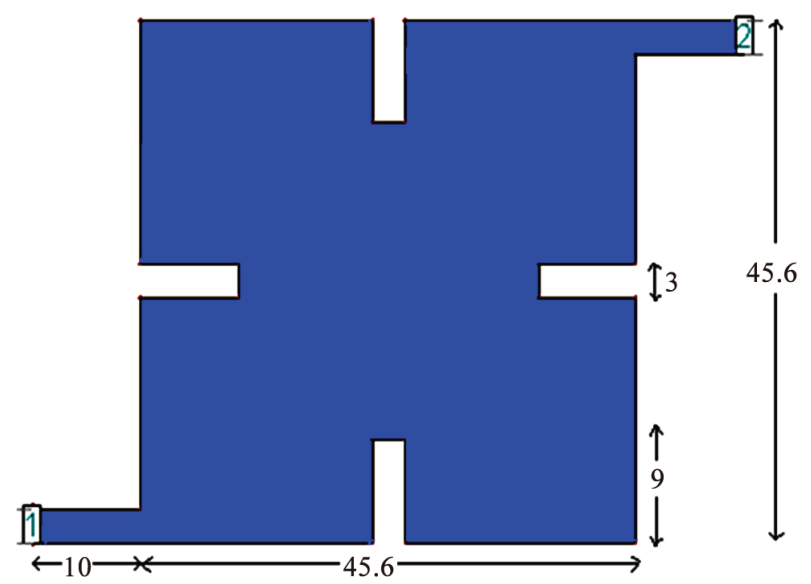

Figure 3. Layout of square patch resonator after etching slots (All dimensions are in $\mathbf{m m}$ )

three modes but the resonance frequency of the mode $\mathrm{TM}^{\mathrm{z}}{ }_{110}$ decreases faster. Therefore, band pass filter behavior can be obtained [7]. This is shown in Figure 4. The resultant size and bandwidth decreases as the slot length increases. The square patch has a length $\mathrm{W}$, while the slots have equal lengths $\mathrm{L}$ and width $\mathrm{S}$. The physical dimensions of the simulated patch are $\mathrm{W}=45.6 \mathrm{~mm}, \mathrm{~L}=$ $9 \mathrm{~mm}$ and $\mathrm{S}=3 \mathrm{~mm}$. Denoting $\mathrm{f}_{1}$ as the resonance frequency of the degenerate modes $\mathrm{TM}_{100}^{\mathrm{z}}$ and $\mathrm{TM}^{\mathrm{z}}{ }_{010}$ and $\mathrm{f}_{2}$ as the resonance frequency of the mode $\mathrm{TM}^{\mathrm{z}}{ }_{110}$. The effect of the slots length $\mathrm{L}$ on the resonance frequencies $f_{1}$ and $f_{2}$ for the patch is that the two resonance frequencies, $f_{1}$ and $f_{2}$, decrease as $L$ increases [7]. The difference $f_{2}-f_{1}$ can be used as first approximation of the possible bandwidth of the filter. For $\mathrm{L}=9 \mathrm{~mm}$, a fractional bandwidth of about $33 \%$ can be obtained using the given pa- rameters.

Based on this design configuration, it is difficult to achieve bandwidth less than this value. However, loading the patch by open circuit stubs as shown in Figure 5 will decrease the resonance frequency $\mathrm{f}_{2}$ of the mode $\mathrm{TM}_{110}^{\mathrm{z}}$ and approximately maintains the resonance frequency of the degenerate modes constant. Therefore, band pass filters with fractional bandwidth less than $25 \%$ can be achieved.

The layout of the filter with the stubs of width $1 \mathrm{~mm}$ and length $12 \mathrm{~mm}$ can be seen in Figure 5. The subsequent effect on the resonance frequencies $f_{1}$ and $f_{2}$ is

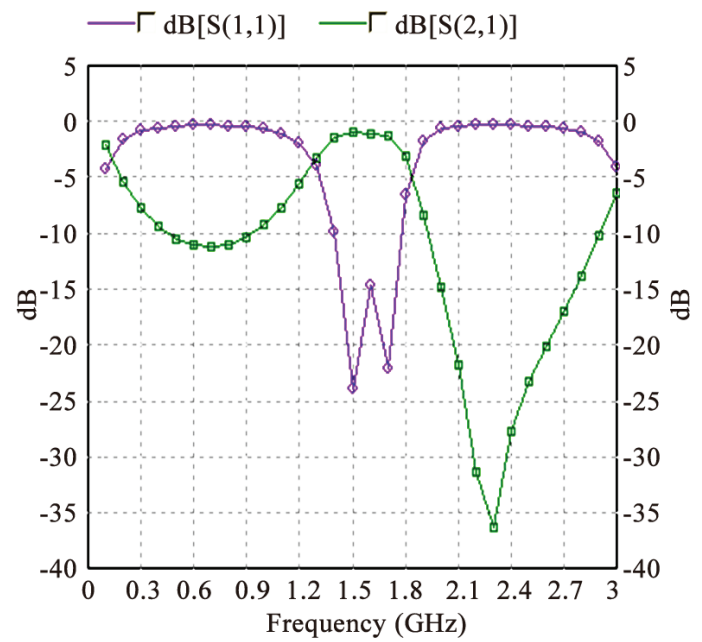

Figure 4. Simulated response of square patch resonator after etching slots

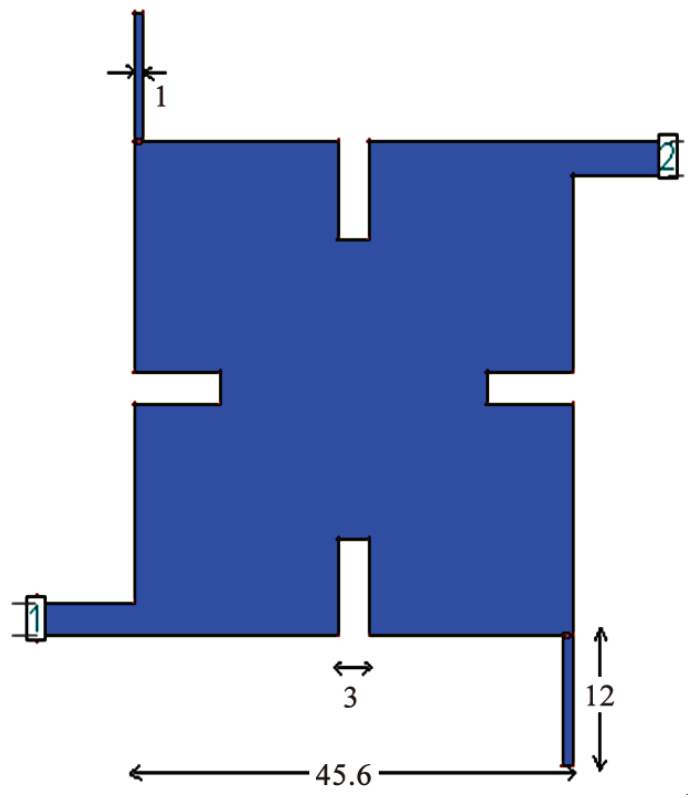

Figure 5. Layout of non-degenerate dual-mode filter with stubs of length $12 \mathrm{~mm}$ 
shown in Figure 6. This analysis is carried out using the moments method IE3D simulator, on a conducting patch of $\mathrm{W}=45.6 \mathrm{~mm}$ on a substrate of dielectric constant 4.4 , with height $1.6 \mathrm{~mm}$. The slot length and width used are 9 $\mathrm{mm}$ and $3 \mathrm{~mm}$, respectively. These parameters have been chosen to fix $\mathrm{f}_{1}$ at $1.3 \mathrm{GHz}$.

As described in the previous section, almost no effect is observed on the resonance frequency of the first two degenerate modes $\mathrm{TM}_{100}^{\mathrm{z}}$ and $\mathrm{TM}^{\mathrm{z}}{ }_{010}$. The resonance frequency of these modes $f_{1}$ is almost constant and equal to $1.3 \mathrm{GHz}$ for stubs length of 0 to $18 \mathrm{~mm}$. However, the first higher order mode $\mathrm{TM}^{\mathrm{z}}{ }_{110}$ is highly affected and its resonance frequency $f_{2}$ decreases. This variation allows the design of narrow band filter, with careful control of its bandwidth. Bandwidth selection can be obtained by first choosing $\mathrm{f}_{1}$ and then finding the appropriate stub lengths for a specific value of $\mathrm{f}_{2}$.

\section{Filter Design Parameters}

For the proposed narrowband band pass filter the design parameters are:

Dielectric Constant $=4.4$,

Height of Substrate $=1.6 \mathrm{~mm}$, $\mathrm{mm}$,

Corresponding length of the Square patch, $\mathrm{W}=45.6$

Corresponding width of the slots, $\mathrm{S}=3 \mathrm{~mm}$,

Corresponding length of the slots, $\mathrm{L}=9 \mathrm{~mm}$,

Corresponding width of the stubs, $\mathrm{W}_{\mathrm{s}}=1 \mathrm{~mm}$,

Corresponding length of the stubs, $\mathrm{L}_{\mathrm{s}}=16 \mathrm{~mm}$,

The layout of the non-degenerate dual-mode filter with stubs of length $16 \mathrm{~mm}$ is shown in Figure 7 and Figure 8 shows the fractional bandwidth obtained is about $20 \%$ in

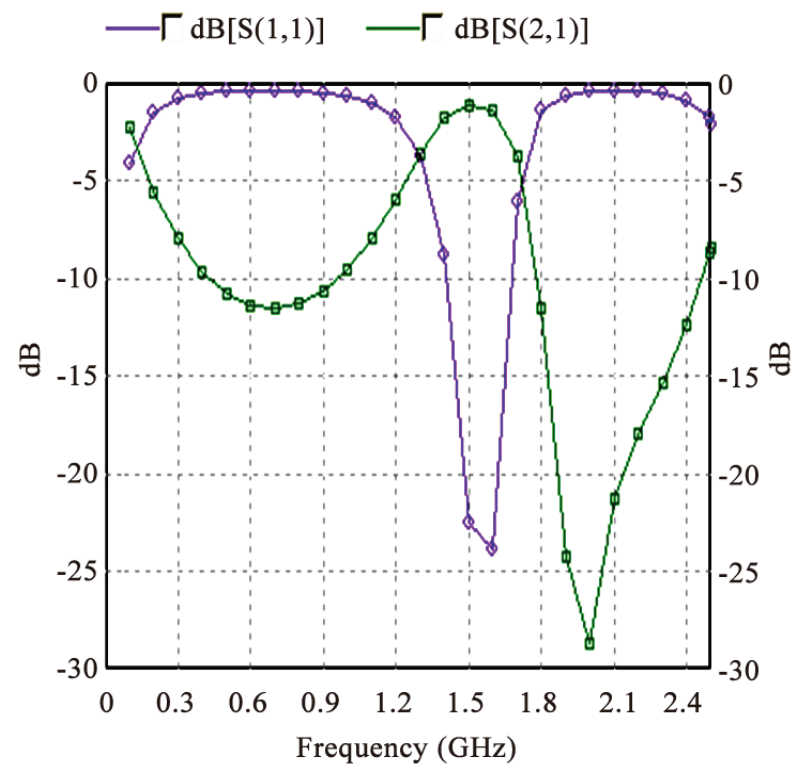

Figure 6. Simulated response of non-degenerate dual-mode filter with stubs of length $12 \mathrm{~mm}$

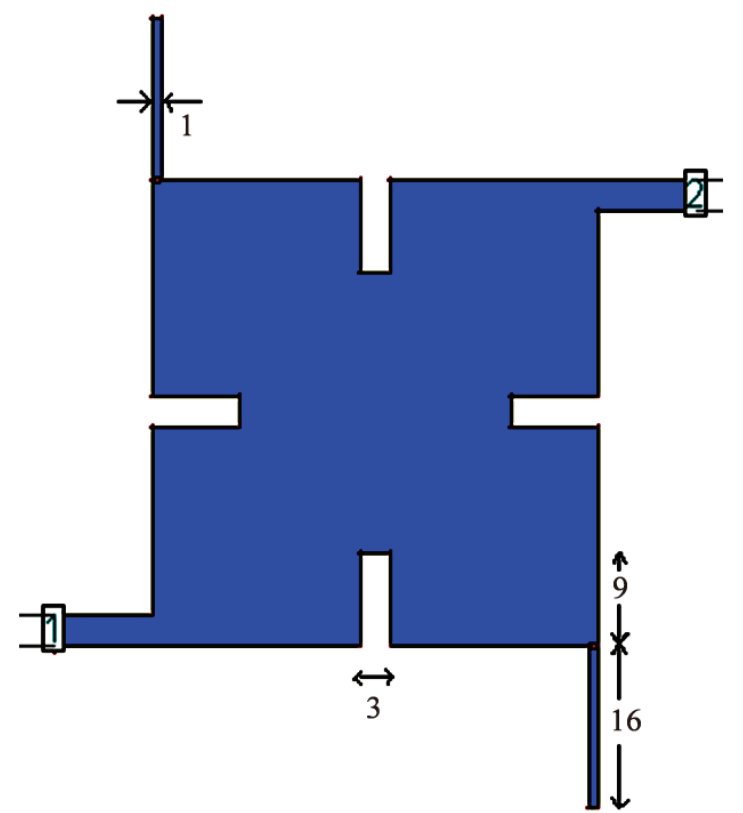

Figure 7. Layout of the dual-mode filter with stubs of length $16 \mathrm{~mm}$

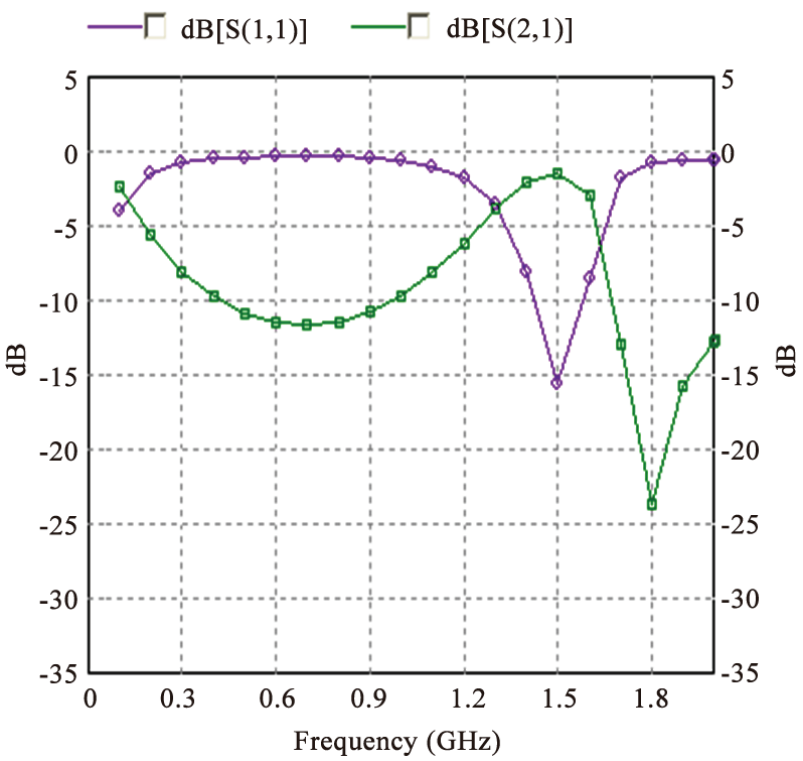

Figure 8. Simulated response of dual-mode filter with stubs of length $16 \mathrm{~mm}$

the passband $1.3 \mathrm{GHz}-1.6 \mathrm{GHz}$ and the return loss is found to be $15.11 \mathrm{~dB}$. The layout as shown in Figure 9, is obtained after etching one square lattice of dimension of $6 \mathrm{~mm} \times 6 \mathrm{~mm}$, on the center of the conventional nondegenerate dual mode filter. The corresponding return loss of the bandpass filter at the center frequency is found to be improved and becomes $22.56 \mathrm{~dB}$. The fabricated layout is shown in Figure 10. The simulated and measured results are shown in Figures 11, 12. 


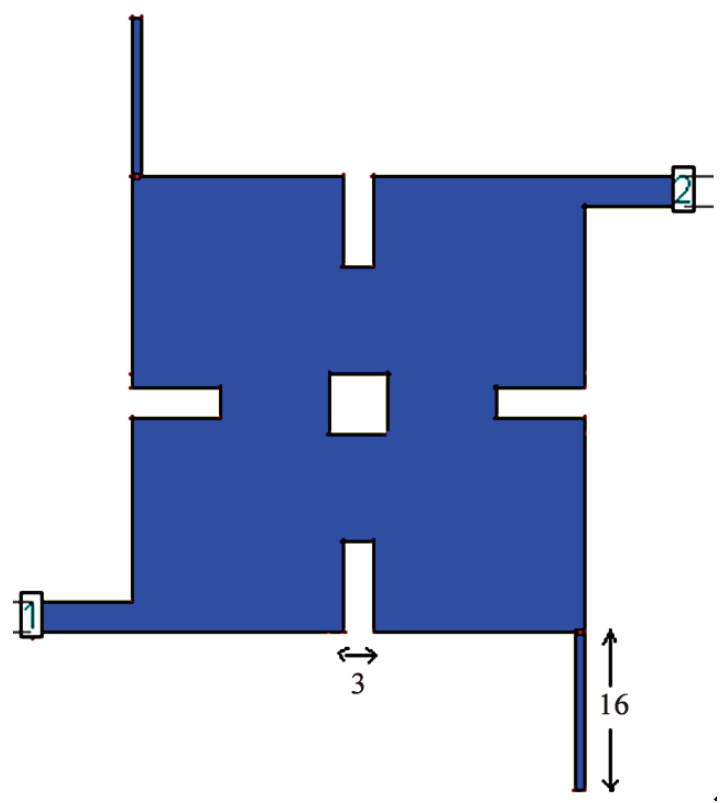

Figure 9. Layout of the non-degenerate dual mode filter with etching of one square lattice

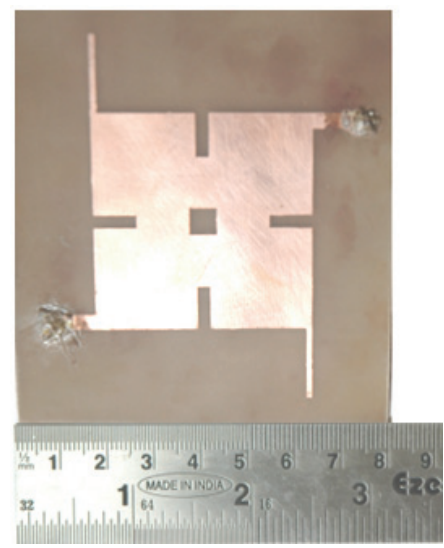

Figure 10. Photographed layout of non-degenerate dual mode filter with etching of one square lattice

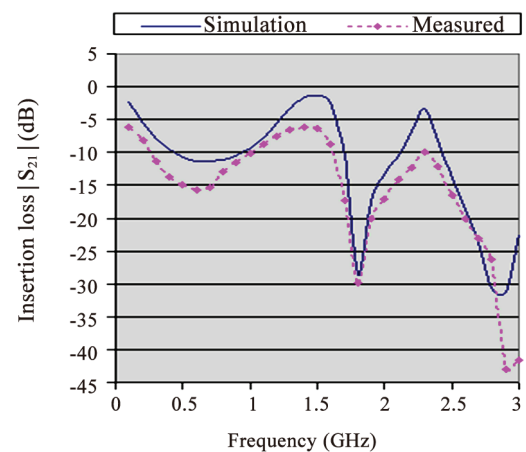

Figure 11. Simulated and measured results of insertion loss of non-degenerate dual mode filter with etching of one square lattice

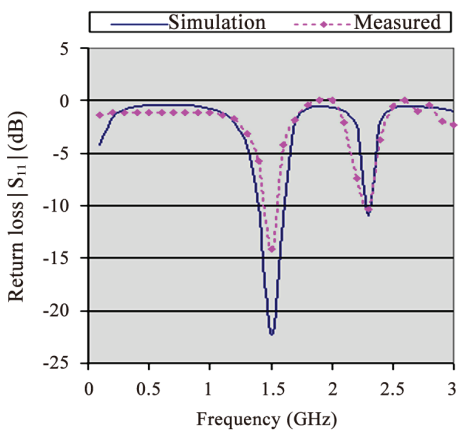

Figure 12. Simulated and measured results of return loss of non-degenerate dual mode filter with etching of one square lattice

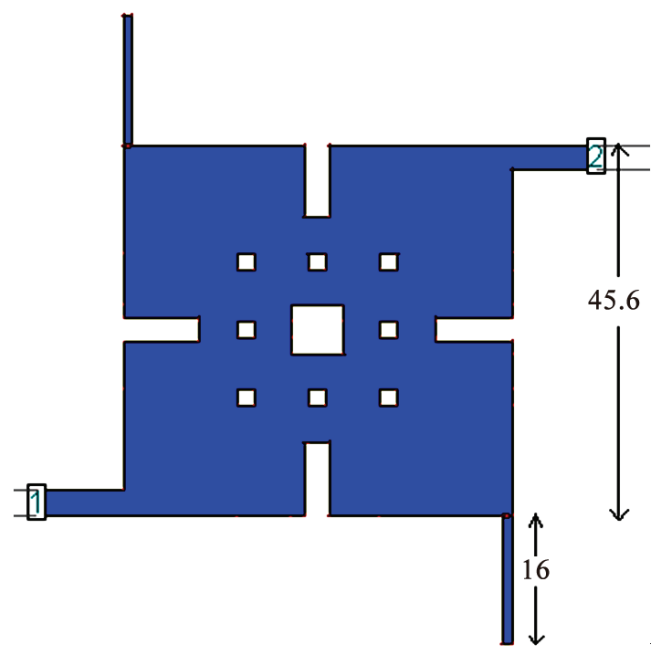

Figure 13. Layout of the non-degenerate dual mode filter with eight square lattices

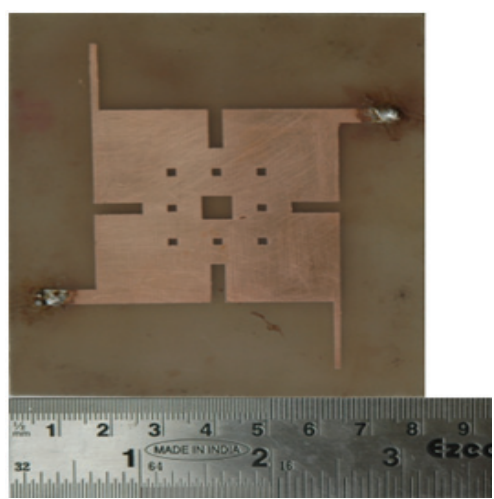

Figure 14. Photographed layout of the non-degenerate dual mode filter with eight square lattices

Now, with additional eight small square lattices of dimension $2 \mathrm{~mm} \times 2 \mathrm{~mm}$ etched as shown in Figure 13, the frequency response can further be improved as shown in Figures 14, 15. The return loss now is $26.12 \mathrm{~dB}$. Figure 
16 shows the fabricated layout of the non-degenerate dual mode filter with eight square lattices.

Figure 17 shows the layout of non-degenerate dual mode filter with a carpet of square lattices of very small dimension $1 \mathrm{~mm} \times 1 \mathrm{~mm}$. It further improves the return loss to $30.06 \mathrm{~dB}$ which is shown in Figure 18.

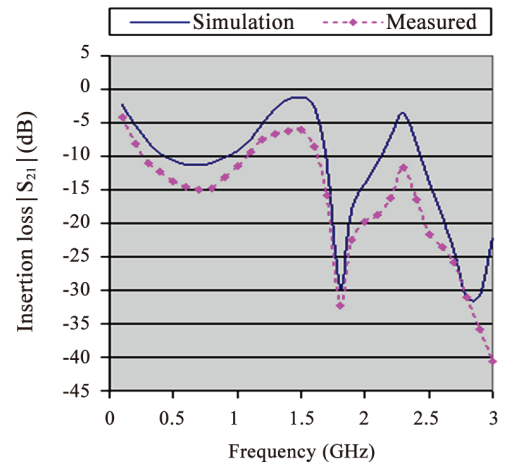

Figure 15. Simulated and measured insertion loss plots for non-degenerate dual mode filter with eight small square lattices

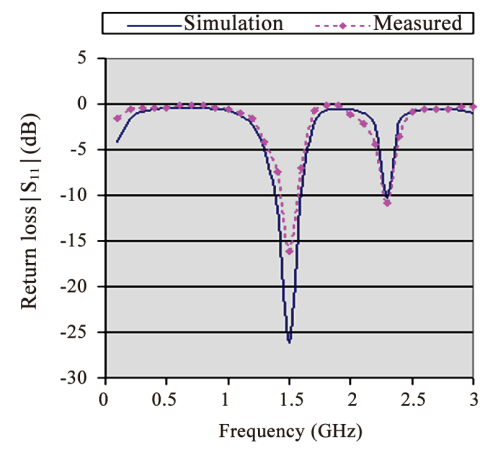

Figure 16. Simulated and measured return loss plots for non-degenerate dual mode filter with eight small square lattices

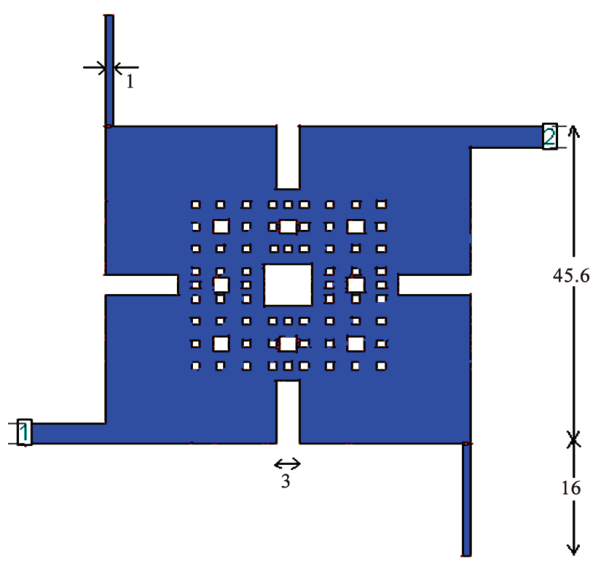

Figure 17. Layout of non-degenerate dual mode filter with carpet square lattices

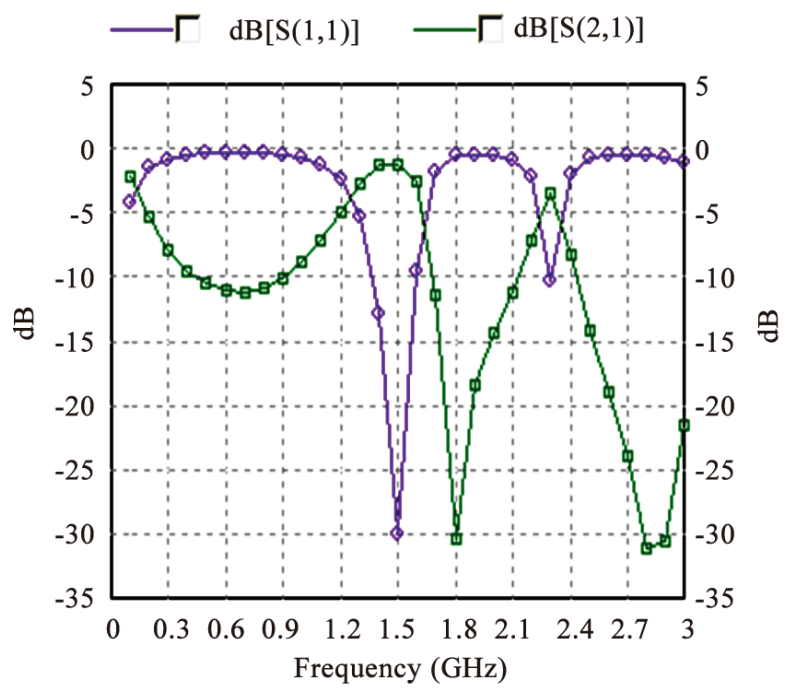

Figure 18. Simulated response of non-degenerate dual mode filter with carpet square lattice

\section{Conclusions}

A compact narrow band filter based on non-degenerate dual-mode resonator is proposed. The narrow bandwidth characteristic is achieved by loading the slotted square patch at opposite corners. Such loading affect only the higher cutoff frequency of the filter. The effect of this loading has been discussed.

For improved performance in terms of return loss for the narrowband band pass filter, square shape lattices of different dimensions etched on the conventional design. It significantly improves the return loss with $30.06 \mathrm{~dB}$ at the center frequency. Hence, a narrowband filter of fractional bandwidth $20 \%$ is designed and implemented with better performance on transmission and reception. Good agreement between simulated and measured responses is observed.

\section{Acknowledgment}

The authors thankfully acknowledge the financial support provided by All India Council of Technical Education, New Delhi, India.

\section{REFERENCES}

[1] I. Wolff, "Microsrtip bandpass filter using degenerate modes of microstrip ring resonator," Electron Letter, Vol.8, No. 12, pp. 302-303, 1972.

[2] J. S. Hong and M. J. Lancaster, "Microstrip filters for RF/Microwave applications," John Wiley \& Sons, Inc., New York, 2001.

[3] J. S. Hong and M. J. Lancaster, "Bandpass characteristics of new dual-mode microstrip square loop resonators," Electronic Letter, Vol. 31, pp. 891-892, 1995.

[4] J. C. Liu, C. S. Cheng, and L. Yao, "Dual-mode dou- 
ble-ring resonator for microstrip band-pass filter design," Microwave Optical Technology Letter, Vol. 36, pp. 310-314, 2003.

[5] J. S. Hong and M. J. Lancaster, "Microstrip bandpass filter using degenerate modes of a novel meander loop resonator," IEEE Microwave Quided Wave Letter, Vol. 5, No. 11, pp. 371-372, 1995.

[6] A. F. Sheta, N. Dib, and A. Mohra, "Investigation of new non degenerate dual-mode microstrip patch filter," IEEE
Proceedings-Microwave Antennas Propagation, Vol. 153, No. 1, pp. 89-95, 2006.

[7] A. F. Sheta, "Narrow band compact non-degenerate dual-mode microstrip filter," 25 th National radio science conference (NRSC'08), Faculty of Engineering, Tanta University, 2008.

[8] G. Mattaei, L. Young, and E. M. T. Jones, "Microwave filters, impedance matching networks, and coupling structures," Artech House, Norwood, MA, 1980. 